\title{
Multiplicação in vitro de Eucalyptus grandis sob estímulo com benzilaminopurina
}

\author{
Wirifran Fernandes de Andrade(1), Marcílio de Almeida(2) e Antônio Natal Gonçalves(1)
}

(1)Escola Superior de Agricultura Luiz de Queiroz (Esalq), Dep. de Ciências Florestais, Av. Pádua Dias, № 11, Caixa Postal 9, CEP 13418-900 Piracicaba, SP. E-mail: wirifran@esalq.usp.br, natalgon@esalq.usp.br (2)Esalq, Dep. de Ciências Biológicas. E-mail: malmeida@esalq.usp.br

\begin{abstract}
Resumo - O objetivo deste trabalho foi avaliar os efeitos do estímulo com benzilaminopurina(BAP) na multiplicação in vitro de Eucalyptus grandis. Foram avaliadas as interações entre concentrações de BAP (0, 200, 400 e $\left.600 \mathrm{mg} \mathrm{L}^{-1}\right)$, tempo de exposição (1, 2 e 3 horas), pH (3 e 5,8) da solução e alterações morfológicas dos explantes. Semanalmente, foi determinada a massa da matéria fresca dos explantes. Aos 21 dias de cultura, foram avaliados: o número de brotações por tratamento, o número de brotações obtidas por explante (taxa de multiplicação), e foi realizado o resgate das plântulas para avaliação histológica. O pH não apresentou interação com os demais fatores estudados. Os tratamentos com BAP a $200 \mathrm{mg} \mathrm{L}^{-1}$, durante 1 e 2 horas, apresentaram-se como os mais indicados na multiplicação do E. grandis. Houve intensificação da divisão celular, no parênquima cortical e no procâmbio, representada pelo surgimento de meristemóides, em resposta aos tratamentos com $200 \mathrm{mg} \mathrm{L}^{-1}$ de BAP, durante 1 e 2 horas. O estímulo com BAP na multiplicação in vitro de E. grandis é viável.
\end{abstract}

Termos para indexação: micropropagação, essência florestal, histologia, regulador vegetal.

\section{In vitro multiplication of Eucalyptus grandis under BAP pulse}

\begin{abstract}
The objective of this work was to evaluate the effect of pulse on in vitro multiplication of Eucalyptus grandis. Interactions were evaluated among BAP concentrations (0, 200, 400 and $\left.600 \mathrm{mg} \mathrm{L}^{-1}\right)$, exposure time (1, 2 and 3 hours), $\mathrm{pH}$ values (3 and 5.8), and explant morphological changes. Fresh weight of the explants was determined weekly. At 21 days of culture, valuations were made of the number of shootings per treatment, number of shootings obtained per explant (multiplication rate), and seedlings rescue was accomplished for histological analysis. The $\mathrm{pH}$ values did not present any interaction with the other factors. The most significant treatments on E. grandis shoot multiplications were $200 \mathrm{mg} \mathrm{L}^{-1}$ of 6-BAP during 1 and 2 hours. There was an intensification of cell division in the cortical parenchyma and procambium, represented by the arising of meristems in response to $200 \mathrm{mg} \mathrm{L}^{-1}$ of BAP treatment, during 1 and 2 hours. The use of the pulse on in vitro multiplication of $E$. grandis is feasible.
\end{abstract}

Index terms: micropropagation, forest essence, histology, plant growth regulator.

\section{Introdução}

Espécies do gênero Eucalyptus têm merecido atenção de empresas e instituições de pesquisa no Brasil devido ao aumento crescente de novos plantios, em função dos ganhos alcançados em produtividade florestal, visando a atender a crescente demanda de madeira destinada a fins energéticos e de produção de celulose e papel (Sociedade Brasileira de Silvicultura, 2005).

Para a propagação vegetativa de Eucalyptus spp., utilizam-se métodos clássicos como estaquia e enxertia. A estaquia tem apresentado alguns problemas relativos ao baixo índice de enraizamento, quando se utiliza ma- terial mais adulto, em razão do acúmulo de inibidores de enraizamento. Porém, mesmo a partir de material jovem, o enraizamento é baixo para algumas espécies de Eucalyptus (Xavier \& Comércio, 1996). Assim, a cultura de tecidos apresenta-se como um método alternativo na propagação de Eucalyptus spp., por oferecer vantagens sobre a estaquia, tais como: taxa mais elevada de multiplicação, menor necessidade de espaço físico, ausência de pragas e doenças, durante o cultivo in vitro, além de ser uma técnica mais segura, graças ao maior controle dos fatores envolvidos (Higashi et al., 2002). 
Um dos fatores a ser otimizado na micropropagação é a redução do tempo de cultura, o que pode auxiliar o processo da propagação in vitro, mesmo sendo, na maioria das vezes, um processo demorado e dispendioso na obtenção do protocolo para cada espécie (Pullman et al., 2003).

O uso de estímulos como ferramenta na micropropagação, sobretudo em Eucalyptus spp., é direcionado à indução de raízes em estacas ou em plântulas micropropagadas. O potencial dessa técnica, na multiplicação de genótipos desse gênero, já foi confirmado e se baseia na exposição do material vegetal a um determinado estresse externo, afim de se obter uma resposta biológica. Esse estresse pode variar em intensidade, duração e concentração, dependendo do objetivo (Eymar et al., 2000; Srivastava et al., 2001; Bennett et al., 2003; Vikranti \& Rashid, 2003; Anthony et al., 2004; Stojičić \& Budimir, 2004). Apesar do grande número de trabalhos com essa ferramenta, nada se conhece sobre o efeito que ocorre no âmbito molecular, durante o tempo em que o material vegetal está sendo tratado, nem quais são os mecanismos que regulam a absorção dos reguladores vegetais; há necessidade, portanto, de mais pesquisas no estudo desse estímulo, principalmente com relação às vias de regeneração.

Em se tratando de multiplicação in vitro de Eucalyptus spp., com o uso de explantes em maior nível de maturação, este trabalho é pioneiro na utilização dessa ferramenta aliada à cultura de tecidos. Este processo visa minimizar o tempo necessário para produção de mudas micropropagadas, o que deve resultar em ganho de produtividade, para empresas que utilizam a micropropagação para produção comercial de mudas.

O objetivo desse trabalho foi avaliar os efeitos do estímulo com benzilaminopurina (BAP) na multiplicação in vitro de Eucalyptus grandis.

\section{Material e Métodos}

Como explantes foram utilizados segmentos nodais com os dois primeiros nós e suas folhas, da região subapical de plântulas de E. grandis, cultivadas in vitro com aproximadamente $2 \mathrm{~cm}$ de altura. O delineamento experimental foi inteiramente casualizado, com 24 tratamentos, que consistiram de quatro concentrações deBAP $\left(0,200,400\right.$ e $\left.600 \mathrm{mg} \mathrm{L}^{-1}\right)$, três tempos de exposição ( 1,2 e 3 horas) e dois valores de $\mathrm{pH}$ (3 e 5,8) da solução, em fatorial $4 \times 3 \times 2$, com cinco repetições, num total de
120 unidades experimentais. Cada unidade experimental foi constituída por um frasco com cinco explantes. A testemunha foi representada pelos tratamentos que não continham concentrações de BAP.

Após a embebição total nos diferentes tratamentos sob agitação em câmara de fluxo laminar, os explantes foram deixados sob papel-toalha para secagem rápida e foram, depois, introduzidos verticalmente em frascos com $40 \mathrm{~mL}$ de meio de cultura JADS (Correia, 1993). As culturas foram mantidas em sala de crescimento, com temperatura de $26 \pm 2^{\circ} \mathrm{C}$, fotoperíodo de 12 horas e iluminância de $50 \pm 2 \mu \mathrm{mol} \mathrm{m} \mathrm{m}^{-2} \mathrm{~s}^{-1}$.

Semanalmente, foram feitas coletas do material in vitro para determinação da massa da matéria fresca dos explantes. Após 21 dias de cultura, avaliaram: número de brotações, por tratamento, e número de brotações obtidas por explante (taxa de multiplicação). Os resultados obtidos foram submetidos à análise de variância, e as médias foram comparadas pelo teste de Tukey, a 5\% de probabilidade. Também, aos 21 dias, fez-se o resgate das plântulas, as quais foram fixadas em solução de Karnovsky (Karnovsky, 1965) para avaliação histológica. Os cortes foram feitos com navalha do tipo C, em microtómo rotativo manual (Leica), com secções longitudinais de $5 \mu \mathrm{m}$ de espessura coradas com azul de toluidina 0,05\% (v/v); em seguida estes cortes foram montados em lâminas histológicas com resina sintética (Entellan). As lâminas histológicas foram fotomicrografadas em microscópico Zeiss, em escala micrométrica.

\section{Resultados e Discussão}

A concentração de BAP e o tempo apresentaram influência direta na multiplicação in vitro de $E$. grandis, ao passo o pH não foi significativo (Tabela 1). O efeito do $\mathrm{pH}$ no meio de cultura tem sido discutido por diversos

Tabela 1. Análise de variância dos dados de número de brotos por tratamento (fatores: concentração de BAP, tempo de exposição e pH), na multiplicação in vitro de Eucalyptus grandis. Coeficiente de variação: 17,33\%.

\begin{tabular}{lrrrc}
\hline Fonte de variação & GL & \multicolumn{1}{c}{ SQ } & QM & Pr>F \\
\hline Concentração (C) & 3 & 36,65 & 0,25 & $<0,0001^{*}$ \\
Tempo (T) & 2 & 19,18 & 0,13 & $<0,0001^{*}$ \\
pH & 1 & 0,18 & 0,18 & 0,5083 \\
CxT & 6 & 2,33 & 14,02 & $0,0002^{*}$ \\
CxpH & 3 & 0,18 & 0,56 & 0,7164 \\
TxpH & 2 & 0,11 & 0,23 & 0,7492 \\
TxpHxC & 6 & 1,07 & 6,47 & 0,0684 \\
Resíduo & 48 & 19,82 & 0,41 & \\
\hline
\end{tabular}

*Significativo a $5 \%$ de probabilidade pelo teste $\mathrm{F}$. 
autores, que destacam sua função na absorção de nutrientes e reguladores vegetais, o que pode afetar a taxa de crescimento dos explantes, durante o tempo de permanência em meio sólido, que geralmente é maior do que quatro semanas (Eymar et al., 2000; Bennett et al., 2003; Anthony et al., 2004). A ausência de significância do $\mathrm{pH}$, neste trabalho, pode ter ocorrido em razão do curto período de exposição dos explantes aos tratamentos com os valores de pHs testados, ou, ainda, por ser o regulador testado uma citocinina. Segundo Pasqual (2001), a absorção de auxinas é proporcional à acidez do meio e à maior diferença entre seu $\mathrm{pH}$ e o do citoplasma da célula, e essa absorção de auxinas não mostra evidências da dependência do pH para absorção das citocininas.

As doses de BAP fornecidas promoveram, de modo geral, um aumento na indução de brotações em E. grandis, cultivadas após 21 dias de os explantes terem sido colocados in vitro. O tratamento com $200 \mathrm{mg} \mathrm{L}^{-1}$, por 1 hora, proporcionou o maior número de brotações, tendo alcançado 35,17 brotos em média por tratamento, tendo diferido apenas do tratamento com $200 \mathrm{mg} \mathrm{L}^{-1}$ por 2 horas. O aumento do número de brotações, por tratamento, foi inversamente proporcional ao aumento da dosagem e do tempo de exposição ao BAP, o que evidencia que as concentrações mais elevadas dessa citocinina foram inibitórias para o processo de multiplicação de E. grandis (Tabela 2).

Tabela 2. Número médio de brotos de Eucalyptus grandis, por tratamento, sob diferentes concentrações de BAP e tempo de exposição, 21 dias após a colocação in vitro dos explantes ${ }^{(1)}$.

\begin{tabular}{ccc}
\hline $\begin{array}{l}\text { BAP } \\
\left(\mathrm{mg} \mathrm{L}^{-1}\right)\end{array}$ & $\begin{array}{c}\text { Tempo de exposição } \\
\text { (horas) }\end{array}$ & $\begin{array}{c}\text { Número de } \\
\text { brotos }\end{array}$ \\
\hline 0 & 1 & $19,83 \mathrm{defg}$ \\
0 & 2 & $21,00 \mathrm{bcdefg}$ \\
0 & 3 & $17,50 \mathrm{fg}$ \\
200 & 1 & $35,17 \mathrm{a}$ \\
200 & 2 & $32,17 \mathrm{abcd}$ \\
200 & 3 & $16,00 \mathrm{fgh}$ \\
400 & 1 & $20,83 \mathrm{cdefg}$ \\
400 & 2 & $8,33 \mathrm{hij}$ \\
400 & 3 & $4,67 \mathrm{ijl}$ \\
600 & 1 & $12,17 \mathrm{ghi}$ \\
600 & 2 & $2,67 \mathrm{jl}$ \\
600 & 3 & 0,171 \\
\hline
\end{tabular}

${ }^{(1)}$ Médias seguidas por letras iguais não diferem entre si, pelo teste de Tukey, a 5\% de probabilidade.
O peso da matéria fresca, entre 7 e 14 dias, teve um ligeiro aumento, porém a maior produção ocorreu entre os 14 e 21 dias de cultivo, o que indica que o desenvolvimento dos brotos ocorreu durante esse período (Figura 1).

Na maioria dos trabalhos com cultura in vitro de essências florestais, com o uso da técnica de "pulse" (Drake et al., 1997; Das et al., 1999; Mathur \& Nadgauda, 1999; Stojičić \& Budimir, 2004), tecidos embriogênicos são utilizados como fonte de explantes por apresentar maior potencial morfogenético, em vez de se usar explantes com maior nível de maturação. Porém os resultados deste trabalho, em que se utilizou material vegetal não-embriogênico ratificam os de Merkle et al. (1997), que avaliaram o efeito do "pulse", em tecidos diferenciados de inflorescência de Liquidambar styraciflua, na indução de embriogênese somática, e constataram sua eficiência.

Pela análise das interações entre concentrações de BAP e tempo de exposição, verificou-se a existência de maior índice de brotações multiplicadas, por explante, nos tratamentos com concentração de $200 \mathrm{mg} \mathrm{L}^{-1}$, quando comparados aos demais tratamentos do experimento. A concentração de $200 \mathrm{mg} \mathrm{L}^{-1}$ de BAP, por 1 hora, produziu 7,03 brotos por explante, e constituiu a maior taxa de multiplicação, seguido de 6,43, por 2 horas de exposição, para a mesma concentração (Figura 2). Stojičić \& Budimir (2004) também encontraram o valor de 4,6 brotos, por explante, desenvolvidos em cotilédones de Pinus heldreichii, e atribuíram esse resultado à interação dos fatores BAP $\left(50 \mathrm{mg} \mathrm{L}^{-1}\right)$ por 1 hora de exposição. O fato de as interações de

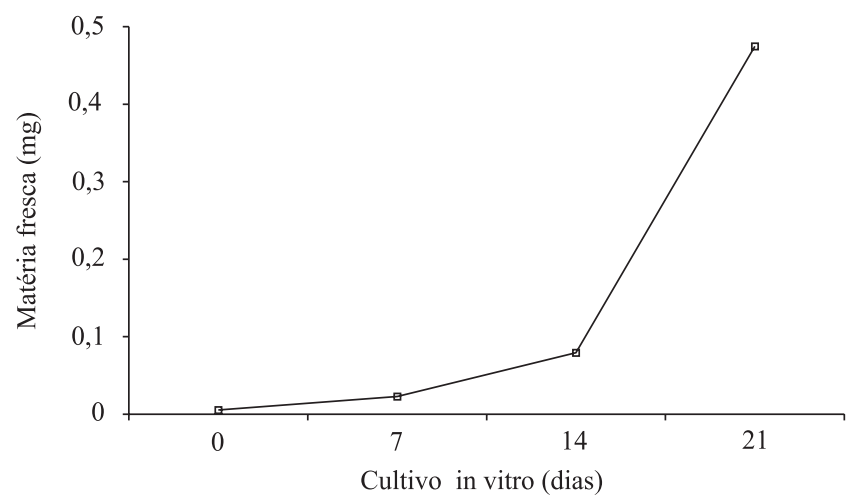

Figura 1. Valores médios referentes à produção de matéria fresca dos explantes de Eucalyptus grandis, no tratamento com $200 \mathrm{mg} \mathrm{L}^{-1}$ de BAP, por uma hora. 
$200 \mathrm{mg} \mathrm{L}^{-1}$ de BAP, durante 1 e 2 horas, terem favorecido o aumento na taxa de multiplicação pode estar relacionado com a atuação desta citocinina na divisão celular, o que favorece o desenvolvimento de brotações laterais.

As análises histológicas foram realizadas nos tratamentos com $200 \mathrm{mg} \mathrm{L}^{-1}$ de BAP por 1 e 2 horas, respectivamente, por serem os tratamentos que melhor responderam às variáveis número de brotações por tratamento e número de brotações por explante. Os demais tratamentos não apresentaram alterações morfológicas consideráveis, quando comparados à testemunha. Nessa região, ocorreu a formação de centros meristemáticos, formados por células pequenas, isodiamétricas, com elevada relação núcleo-plasmática (RNP), características de regiões meristemáticas com intensa atividade de divisão celular (Cutter, 1987). Em conseqüência da formação dos centros meristemáticos, a região basal dos explantes sofreu completa desestruturação, tendo alterado a composição dos tecidos internos, principalmente do parênquima cortical e do procâmbio, o que permite atribuir a esses tecidos a principal capacidade de resposta morfogênica aos tratamentos (Figura 3). Segundo Hicks (1980), a competência celular para determinadas respostas morfogenéticas in vitro pode ser intrínseca ao explante

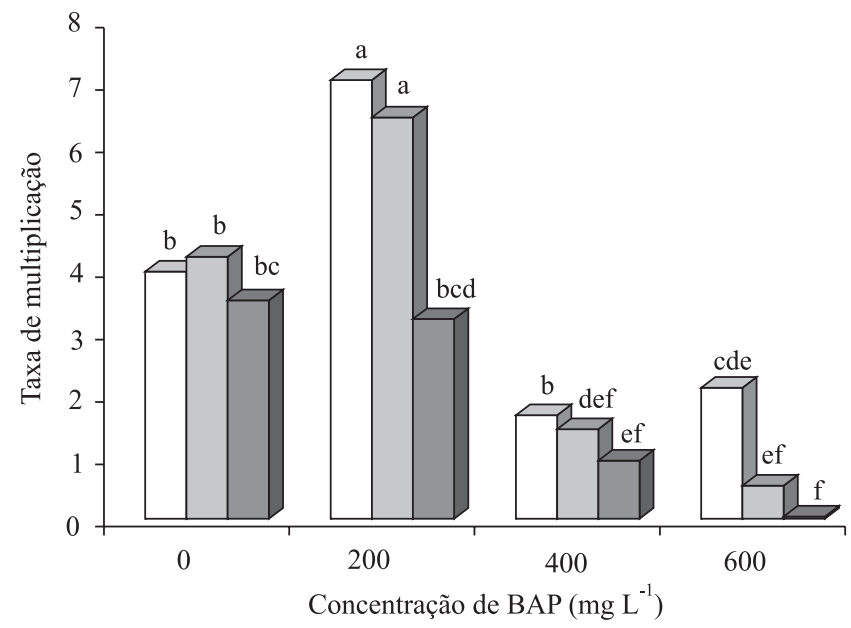

$\square$ 1 hora $\quad \square 2$ horas $\quad \square 3$ horas

Figura 2. Número médio de brotações por explante (taxa de multiplicação) de Eucalyptus grandis, sob diferentes concentrações de BAP e tempo de exposição, após 21 dias da colocação dos explantes in vitro. Médias com letras iguais não diferem entre si, pelo teste de Tukey, a 5\% de probabilidade.
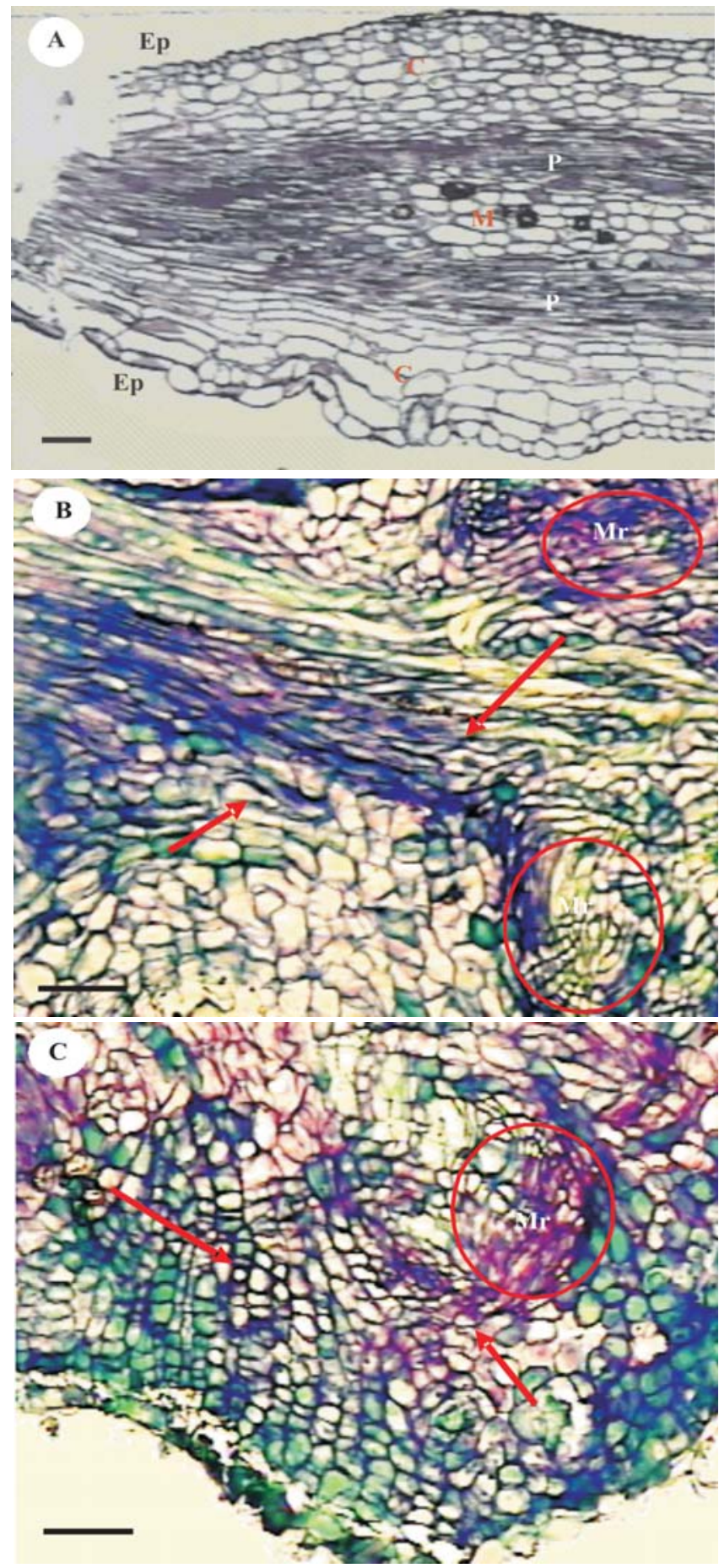

Figura 3. Fotomicrografia, em microscópio Zeiss, do corte transversal da região basal do explante de Eucalyptus grandis, destacando-se a formação de meristemóides, após cultivo por 21 dias nos seguintes tratamentos: A) testemunha; B) $200 \mathrm{mg} \mathrm{L}^{-1}$ de BAP, por 1 hora; C) $200 \mathrm{mg} \mathrm{L}^{-1}$ de BAP, por 2 horas. Ep: epiderme; C: córtex; P: procâmbio; Mr: meristemóide. Setas: região cortical com elevada atividade meristemática. Barras $=100 \mu \mathrm{m}$. 
utilizado, como é o caso do periciclo e a formação das raízes laterais, ou então induzida por meio de manipulações adequadas.

\section{Conclusões}

1. O uso de estímulo com benzilaminopurina (BAP) na concentração de $200 \mathrm{mg} \mathrm{L}^{-1}$, durante 1 e 2 horas de exposição, é eficiente na multiplicação in vitro de Eucalyptus grandis.

2. O pH da solução de BAP de 3,0 e 5,8 não influencia a multiplicação in vitro de Eucalyptus grandis.

\section{Referências}

ANTHONY, J.M.; SENARATNA, T.; DIXON, K.W.; SIVASITHAMPARAM, K. Somatic embryogenesis for mass propagation of Ericaceae a case study with Leucopogon verticillatus. Plant Cell, Tissue and Organ Culture, v.76, p.137-146, 2004.

BENNETT, I.J.; McDAVID, D.A.J.; McCOMB, J.A. The influence of amonium nitrate, $\mathrm{pH}$ and indole butyric acid on root induction and survival in soil of micropropagated Eucalyptus globulus. Biologia Plantarum, v.47, p.355-360, 2003.

CORREIA, D. Crescimento e desenvolvimento de gemas na multiplicação de Eucalyptus spp. in vitro em meio de cultura líquido e sólido. 1993. 113p. Dissertação (Mestrado) - Escola Superior de Agricultura Luiz de Queiroz, Piracicaba.

CUTTER, E.G. Anatomia vegetal: órgãos, experimentos e interpretações. São Paulo: Roca, 1987. 336p.

DAS, D.K.; PRAKASH, N.S.; BHALLA-SARIN, N. Multiple shoot induction and plant regeneration in litchi (Litchi chinensis Sonn.). Plant Cell Reports, v.18, p.691-695, 1999.

DRAKE, P.M.W.; JOHN, A.; POWER, J.B.; DAVEY, M.R. Cytokinin pulse-mediated shoot organogenesis form cotyledons of Sitka Spruce [Picea sitchensis (Bong.) Carr.] and high frequency in vitro rooting of shoots. Plant Cell, Tissue and Organ Culture, v.50, p.147-151, 1997.

EYMAR, E.; ALEGRE, J.; TORIBIO, M.; LÓPEZ-VELA, D. Effect of activated charcoal and 6-benzyladenine on in vitro nitrogen uptake by Lagerstroemia indica. Plant Cell, Tissue and Organ Culture, v.63, p.57-65, 2000.

HICKS, G.S. Patterns of organ development in plant tissue culture and the problem of organ determination. Botanical Review, v.46, p.1-23, 1980.

HIGASHI, E.N.; SILVEIRA, R.L.A. de; GONÇALVES, A.N. Nutrição e adubação em minijardim clonal hidropônico de Eucalyptus. Piracicaba: IPEF, 2002. 21p. (IPEF. Circular técnica, 194).

KARNOVSKY, M.J.A formaldehyde-glutaraldehyde fixative of high osmolality for use in electron microscopy. Journal of Cell Biology, v.1, p.137-138, 1965.

MATHUR, G.; NADGAUDA, R. In vitro plantlet regeneration from mature zygotic embryos of Pinus wallichiana A. B. Jacks. Plant Cell Reports, v.19, p.74-80, 1999.

MERKLE, S.A.; BAILEY, R.L.; PAULEY, B.A.; NEU, K.A.; KIM, M.K.; RUGH, C.L.; MONTELLO, P.M. Somatic embryogenesis from tissues of mature sweetgum trees. Canadian Journal of Forest Research, v.27, p.959-964, 1997.

PASQUAL, M. Cultura de tecidos vegetais: tecnologia e aplicações. Lavras: Ufla, 2001. 92p.

PULLMAN, G.S.; MONTELLO, P.; CAIRNEY, J.; XU, N.; FENG, $\mathrm{X}$. Loblolly pine (Pinus taeda L). somatic embryogenesis: maturation improvements by metal analyses of zygotic and somatic embryos. Plant Science, v.164, p.955-969, 2003.

SOCIEDADE BRASILEIRA DE SILVICULTURA. Silviculture-se. Disponível em: <http://www.sbs.org.br/>. Acesso em: 26 out. 2005.

SRIVASTAVA, K.; TIWARI, K.N.; SINGH, R.; SINGH, B.D.; JAISWAL, H.K. Shoot regeneration from immature cotyledons of Cicer arietinum. Biologia Plantarum, v.44, p.333-337, 2001.

STOJIČIĆ, D.; BUDIMIR, S. Cytokinin-mediated axillary shoot formation in Pinus heldreichii. Biologia Plantarum, v.48, p.477479, 2004.

VIKRANT; RASHID, A. Somatic embryogenesis or shoot formation following high 2,4-D pulse-treatment of mature embryos of Paspalum scrobiculatum. Biologia Plantarum, v.46, p.297-300, 2003.

XAVIER, A.; COMÉRCIO, J. Microestaquia: uma maximização da micropropagação de Eucalyptus. Revista Árvore, v.20, p.9-16, 1996.

Recebido em 13 de fevereiro de 2006 e aprovado em 17 de agosto de 2006 